\title{
A new leak-tight borehole casing at Dome Concordia station, Antarctica, for the SUBGLACIOR project
}

\author{
Romain DUPHIL, Philippe POSSENTI, Luc PIARD \\ Laboratoire de Glaciologie et Géophysique de l'Environnement (LGGE), Université Grenoble Alpes and Centre National de la \\ Recherche Scientifique (CNRS), Grenoble, France \\ E-mail: duphil@lgge.obs.ujf-grenoble.fr
}

\begin{abstract}
In the frame of the SUBGLACIOR project, a new type of casing has been installed for testing during the 2013/14 austral summer season at Dome Concordia station, Antarctica. The SUBGLACIOR probe requires a full fluid column up to the surface, in order to circulate fluid for icechips recovery. This makes it essential that the casing is leak-tight through the porous firn column. We have evaluated existing solutions before opting to test a new method. This new system is made of polyethylene pipes which are welded together at the surface while the casing pipes are lowered into the reamed borehole. It is simple and lightweight and allows the casing to be installed quickly with optimum chance of being leak-tight. The installed casing has been tested both with compressed air and drilling fluids and has proven to work.
\end{abstract}

KEYWORDS: ice coring

\section{INTRODUCTION}

Most ice-core intermediate or deep drilling projects require use of a drilling fluid to prevent borehole closure due to ice pressure. The fluid is dropped into the borehole from the surface using a basic pumping system. To prevent leakage through the porous firn layer the borehole needs to be cased throughout the first $\sim 60-120 \mathrm{~m}$ until the pore close-off depth of the ice is reached.

For the SUBGLACIOR (in SitU proBing of GLACier Ice for a better understanding of the Orbital Response of climate) project (Alemany and others, 2014) a lightweight and watertight casing is needed. In this project, drilling fluid will not only serve to compensate for the ice pressure in the borehole, it will also be essential to transport the drilled ice chips from the drill head up to the surface through a constant upward flow of the fluid column. As this circulating flow must reach the ice-sheet surface, a fully watertight casing is necessary. Weight and volume of the casing must also be optimized in order to limit the logistical requirement of the whole project.

The new type of casing developed by LGGE's (Laboratoire de Glaciologie et Géophysique de l'Environnement) technical group has been tested for the first time at Concordia station, Antarctica, during the 2013/14 austral summer field season. Watertightness tests conducted during the same season showed promising results. The following description of this new casing should benefit the ice-drilling community at large for upcoming projects.

\section{OVERVIEW OF EXISTING CASING SYSTEMS}

The main characteristics considered for the SUBGLACIOR casing are its leak-tightness and its logistic footprint (dimensions and weight). Below we describe the existing systems and how they meet these two requirements.

\section{Steel casing}

Steel casing was used during the Dye-3 drilling project in Greenland (Rand, 1980). It was made with 7 in $(180 \mathrm{~mm})$ outer diameter (OD) steel tubes, manually welded together at each end. Its sealing with the ice at the bottom was obtained by filling water into the lower $0.5 \mathrm{~m}$ of the casing and letting it freeze. Unfortunately this casing leaked on several connections and at the bottom (Johnsen and others, 1994).

\section{Fiberglass tubes}

This type of casing has been used most frequently during the past decade. It has been used in Greenland for the GRIP (Greenland Ice Core Project; Johnsen and others, 1994), NorthGRIP and NEEM drilling projects and in Antarctica, for the Vostok (Kudryashov and other, 2002), EPICA Dome C (Augustin and Antonelli, 2002) and Dronning Maud Land, and Dome Fuji (Fujii and others, 2002) drilling projects.

The casing is made from fiberglass tubes held together by a steel wire. Between each section a double O-ring ensures the sealing of the junction. The inner diameter (ID) is $200 \mathrm{~mm}$ and it requires a $225 \mathrm{~mm}$ borehole. In most applications, the sealing at the bottom of the casing (between tubes and ice) is due to the pressure exerted by the casing itself (from the weight of the casing which amounts to $\sim 10 \mathrm{~kg} \mathrm{~m}^{-1}$ ).

On two occasions sealing to the ice was achieved differently. At Vostok, a special device was constructed to melt a small amount of ice, using heating elements, leaving it to refreeze afterwards (Kudryashov and other, 2002). A similar process was used at Dome Fuji where the casing was sealed at the bottom by refreezing wet snow (Fujii and others, 2002).

Fiberglass tubes are tight enough for classical drilling and have been successfully used, but none of them has seen a fluid column up to the surface. Such an attempt was made at Vostok station but it was not possible to raise the liquid level above $42 \mathrm{~m}$. A leakage at $70 \mathrm{~m}$ depth has also been detected in the EPICA Dome C casing.

Another type of fiberglass casing has been used at Dome A (Zhang and others, 2014). Seventeen $6 \mathrm{~m}$ long pipes were installed in the pilot hole down to $100 \mathrm{~m}$ depth. The tubes were connected together with a four-threaded connection (M218-6 mm) and sealed with fluoroplastic tape. This type 


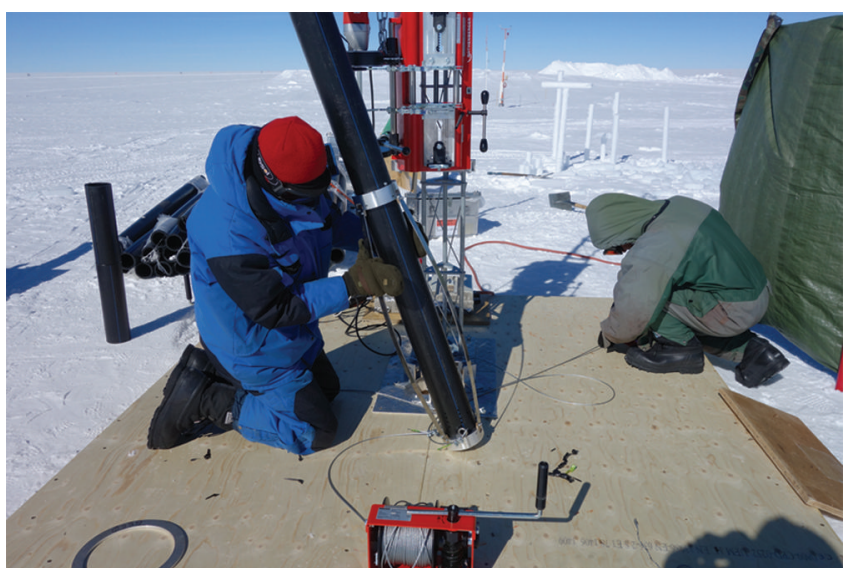

Fig. 1. Anti-torque blade.

of casing has not been filled by drilling fluid, and its leaktightness is not yet proven.

\section{Light fiber pipes casing}

A light version of the former type of casing has been used at Berkner Island and Talos Dome, Antarctica (Mulvaney and others, 2007). It was based on $3 \mathrm{~m}$ long sections $(200 \mathrm{~mm}$ ID, $3 \mathrm{~mm}$ wall thickness and $216 \mathrm{~mm}$ OD at the joint). The sections were not bonded together. They were lowered into the borehole with three $1.5 \mathrm{~mm}$ diameter stainless-steel wires (attached on a stainless-steel cap which is placed at the tip of the first section) using small manual winches. This casing was very light $\left(\sim 2.5 \mathrm{~kg} \mathrm{~m}^{-1}\right)$, but was not tight.

\section{HDPE (high density polyethylene) pipes casing}

HDPE pipes (up to $241 \mathrm{~mm}$ ID and $273 \mathrm{~mm}$ OD in the first $90 \mathrm{~m}$ ) have been used for the West Antarctic Ice Sheet (WAIS) Divide deep drilling project (WAIS Divide end-ofseason field report, www.waisedivide.unh.edu/fieldreports). The same type of pipes with smaller diameter (219 mm OD, $192 \mathrm{~mm}$ ID) are planned to be used by IDDO (Ice Drilling and Design Office, Madison, WI, USA) in the frame of their new intermediate-drill project (Johnson and others, 2014). Again, the connection between the pipes will be made through threaded sections.

The casing is sealed to the ice by a face seal and three external O-rings made from silicon. When these rings are in contact with drilling fluid, they will expand and create a seal with the ice. The whole system is lowered in the borehole using the winch and tower of the intermediate drilling system.

In the frame of the SUBGLACIOR project, the most promising casing in terms of tightness between junctions appeared to be the HDPE pipes. A welded plastic connection is more likely to ensure tightness with time. Long-period testing (10 weeks) of compatibility between HDPE pipes and silicon oil, the drilling fluid deployed with the SUBGLACIOR probe, has been performed with no apparent problem.

\section{DESCRIPTION OF THE SUBGLACIOR CASING}

The casing is made of commercial $6 \mathrm{~m}$ long high-density polyethylene tubes. Originally intended for carrying water in distribution networks, these tubes are shockproof. They can withstand high pressure (6.3-10 MPa, depending on the HDPE type used, from PE 63 to PE 100) and can be easily

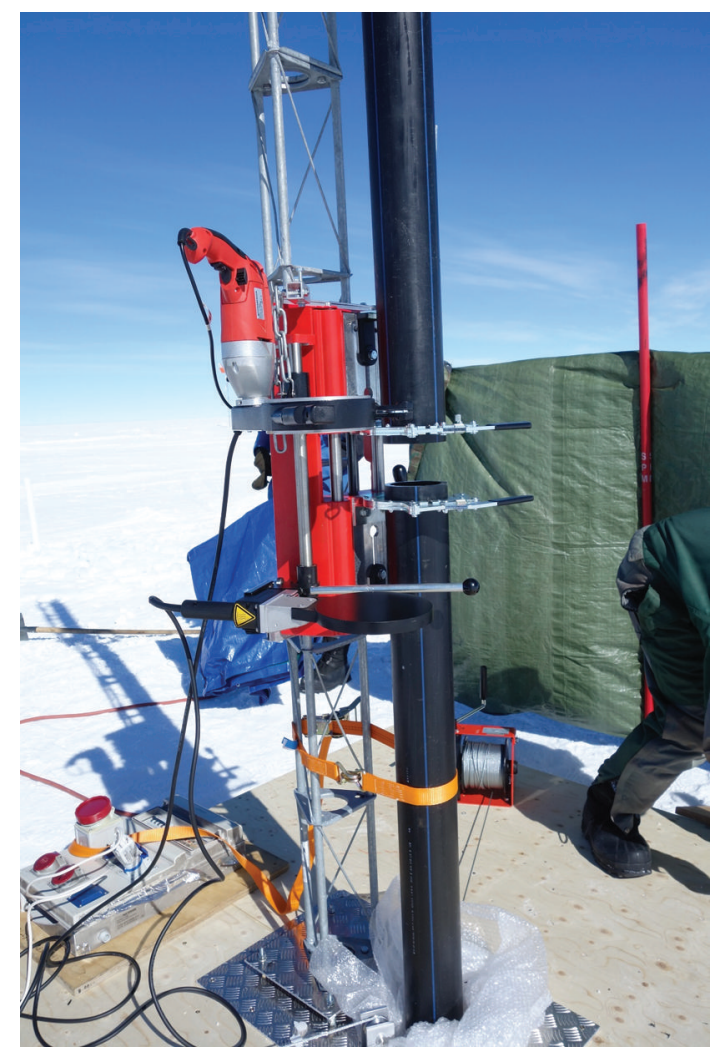

Fig. 2. Soldering system.

welded together. We chose HDPE 80 pipes, which are able to withstand $8 \mathrm{MPa}$. They have been cut into $3 \mathrm{~m}$ long sections to make transportation and field handling easier.

Various diameters are available and compatible with our welding system. Our choice focused on two diameters:

ID of $100 \mathrm{~mm}$ for a $125 \mathrm{~mm}$ OD in the frame of the testing season of the casing;

ID of $130 \mathrm{~mm}$ for a $165 \mathrm{~mm}$ OD for the casing of the fullscale drilling season with the SUBGLACIOR probe.

In order to prevent the casing from tilting in the borehole, three sets of blades (Fig. 1) have been set up on both the lower, the middle and the higher pipes of the casing. These blades help to center the whole casing in the borehole. The free space between borehole wall and casing allows us to compensate for misalignment. The pipe assembly relies on a commercial welding system (ROWELD ${ }^{\circledR}$ P 160 SANILINE, which is sold by Rothenberger) (Fig. 2). It includes a platform with clamps, several sets of flanges, a heating device and a trimmer. The whole welding device has been set up on a welding platform.

The technical specifications of this welding machine are given in Table 1, and the welding process between pipes is shown in Figure 3. When polyethylene tubes are connected using heat fusion welding, shoulders are built up on the inner and outer pipe walls. These inner shoulders should be removed mechanically by the head of the SUBGLACIOR probe, specially designed for reaming.

The welding platform is a $3 \mathrm{~m} \times 3 \mathrm{~m}$ wooden floor with a $350 \mathrm{~mm}$ diameter hole in the center. A mast aligned with the central opening maintains the welding device above and perpendicular to the borehole, for a good alignment before welding. A winching system guides the casing tubes during descent and holds them in place during the welding 
Table 1. Technical specifications of the welding system

$\begin{array}{lc}\text { Working range } & \text { Diameter 40, 50, 56, 63, 75, 90, 110, } \\ & 125,160,180,200,225,250 \mathrm{~mm} \\ \text { Heating power } & 1200 \mathrm{~W} \\ \text { Milling power } & 450 \mathrm{~W} \\ \text { Heater pressure } & 100 \mathrm{~N} \\ \text { Heater pressure time } & 3 \mathrm{~min} \\ \text { Welding pressure } & 160 \mathrm{~N} \\ \text { Welding time } & 10 \mathrm{~min} \\ \text { Total weight of the system } & 131 \mathrm{~kg} \\ \text { Power supply } & 230 \mathrm{Va} \text { a.c. }\end{array}$

operations. It relies on three winches placed at $120^{\circ}$ around the opening and $1.5 \mathrm{~m}$ away from it. The three winches' cables are also guided by three pulleys that are placed along the same axis, flush with the opening in the platform center. The tubes are lowered down the borehole with three $1.5 \mathrm{~mm}$ diameter stainless-steel wires (attached on a stainless-steel cable which is placed at the tip of the first section) using the three small manual winches synchronously. Each cable is rated to a total weight of $600 \mathrm{~kg}$.

\section{OPERATIONAL PROCEDURE DURING THE TEST SEASON}

In the frame of the SUBGLACIOR project, we organized a casing test season during the 2013/14 austral summer at Concordia station.

\section{Drilling the pilot hole}

The drilling system used is the Grenoble $200 \mathrm{~m}$ electromechanical shallow drill, which provides $0.8-1.2 \mathrm{~m}$ long (depending on drilling depth) and $100 \mathrm{~mm}$ diameter ice core for a $138 \mathrm{~mm}$ borehole diameter. The main characteristic of this drilling system is the manual hydraulic gearbox of the winch. We drilled a pilot hole down to $120 \mathrm{~m}$ in $<5$ days.

\section{Reaming}

We progressively increased the borehole diameter from $138 \mathrm{~mm}$ to $250 \mathrm{~mm}$. The reamer is made of a special head where different sets of 'spoon cutters' can be mounted (Fig. 4). In addition, longer anti-torque blades were mounted on the shallow drill (Fig. 5). Unlike other reaming systems (Johnsen and others, 1980), our reaming procedure did not include a tank at the tip of the reamer to collect ice chips

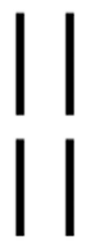

1

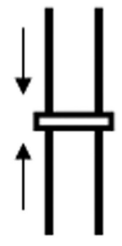

2

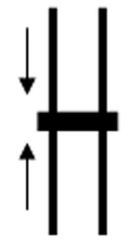

3

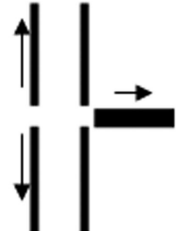

4

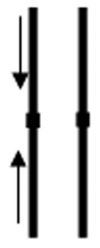

5
Fig. 3. Pipe-welding process. 1: set up the pipes; 2 : face the front side of the pipes with the trimmer; 3: place the heating element between the two pipes, bring the pipe ends together and keep the pressure on the pipe during the heating (pressure and duration of heating depend on the pipe size and material); 4: release the pressure and remove the heating element; 5 : move the pipe ends together again and maintain pressure during the cooling period.

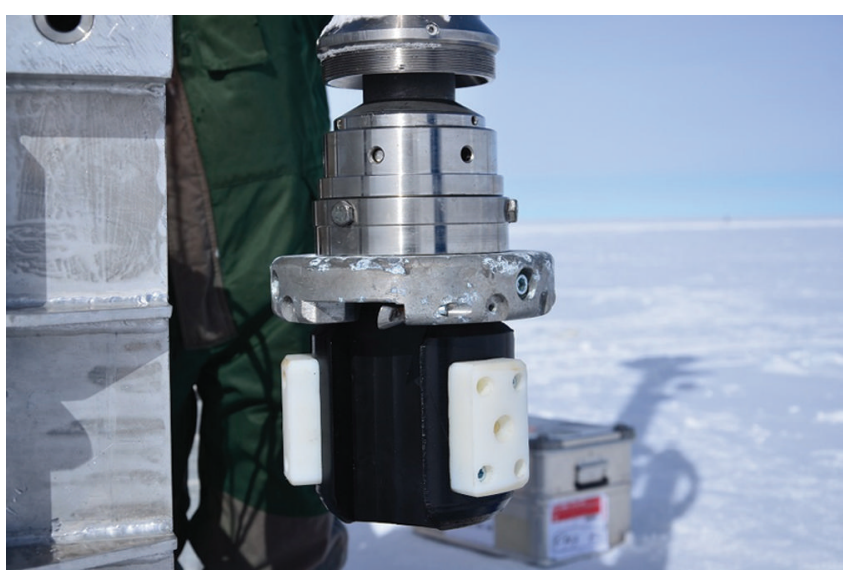

Fig. 4. Reaming head.

generated while increasing the borehole diameter. Thus, all ice chips we produced fell to the bottom of the borehole. After several reaming runs, chips were collected through 'empty core' runs with the shallow drill.

In order to enlarge the pilot hole up to its final diameter, five different sets of cutters have been mounted on the reaming head: 155/175/200/225/250 $\mathrm{mm}$. The borehole diameter was enlarged to $250 \mathrm{~mm}$ down to $109 \mathrm{~m}$ depth in $<10$ days. This reaming diameter was chosen in case the HDPE pipes are misaligned or deformed while welding.

\section{Setting up the casing}

The whole casing was lowered down the borehole by the three manual winches described before. The pipes were welded together following the procedure described in Figure 3. Its sealing at the bottom was ensured by dropping

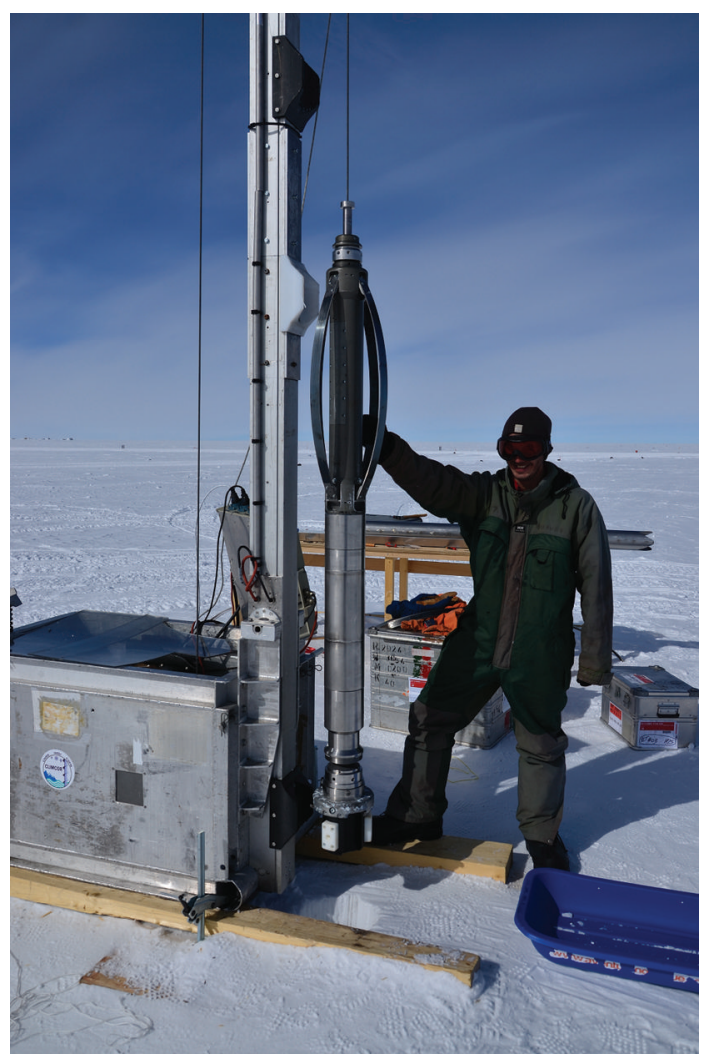

Fig. 5. Reamer. 


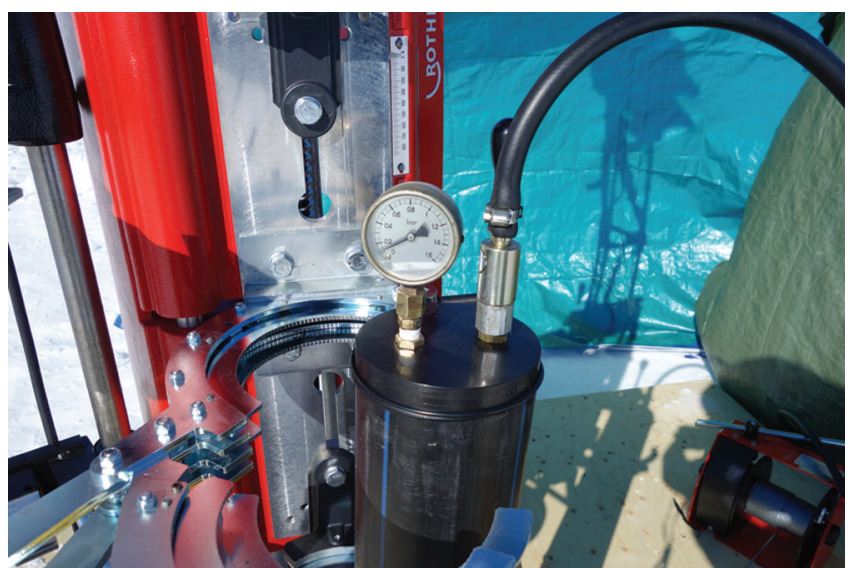

Fig. 6. Polyethylene cap for testing.

$100 \mathrm{~L}$ of hot water at the bottom of the borehole using a pipe and a small hydraulic pump, and by letting it refreeze for 72 hours. Three days were required to set up the casing platform and install the casing.

\section{CASING TIGHTNESS TESTS}

The tightness has been tested with air and drilling fluid.

\section{Air-tightness test}

A polyethylene cap was welded at the top of the casing in order to seal it at both ends (Fig. 6). It included a pressure gauge and a quick air system connector on the upper face, attached to an air compressor unit.

The test was conducted over 3 days. The initial pressure setting of $0.15 \mathrm{MPa}$ remained unchanged throughout the test. This confirms that our casing set-up did not include a significant leak.

\section{Watertightness test}

The casing was entirely filled with D30 kerosene drilling fluid. Due to the fluid contraction relative to the temperature difference between the kerosene drums outside and the inner borehole, the fluid level decreased by $7 \mathrm{~m}$ during the first 12 hours of the experiment. It then remained constant throughout the remaining field season $(\sim 4$ weeks). The pressure at the bottom of the casing was close to $0.9 \mathrm{MPa}$. We checked this fluid level at the beginning of the 2014/15 austral summer season, and it has not changed since last season. The level is still $7 \mathrm{~m}$ below the surface.

\section{Tightness of the sealing}

We still have to check tightness of the sealing. This will be done by drilling through the refrozen water cap at the bottom of the casing during the 2014/15 austral sumer season.

\section{CONCLUSION}

The casing system deployed for the SUBGLACIOR project is relatively easy to set up. It requires $<2$ weeks to drill the pilot hole, to ream it and to set up the casing. Another advantage of this casing is its price: it cost only $€ 5000$ to buy the HDPE pipes and the soldering system.

After testing tightness of the casing both with compressed air and with kerosene drilling fluid raised to the surface, it appears that the casing is not leaking, neither along the tubes nor on the tube junctions. The drilling fluid level of this test casing has been checked 1 year after being set up (at the beginning of the 2014/15 austral summer season) and is still the same. We did not notice any leakage on the refrozen water cap at the bottom of the borehole. We plan to drill through the refrozen water cap, in order to check the tightness of this sealing and to ensure that no crack will be formed during this process.

To our knowledge, this is the first time that a drilling fluid column has been raised up to the surface of a polar ice sheet without leaks out of the casing.

\section{ACKNOWLEDGEMENTS}

The research leading to these results has received funding from the European Community's Seventh Framework Programme ERC2011 under grant agreement No. 291062 (ERC ICE\&LASERS) and from the French Agence Nationale de la Recherche under grant agreement No. SIM15-6-ANR-11BS56-0019 (ANR SUBGLACIOR). This project was conducted with the technical support of the French Drilling and Coring Facility (C2FN - Ice). Additional funding support was provided by the BNP Paribas Foundation as well as 'Equipement d'Excellence' EquipEX CLIMCOR (ANR-11EQPX-0009-CLIMCOR). Fieldwork is supported by IPEV (Paul-Emile Victor Institute, erstwhile French Polar Institute) (France, through 'SUBGLACIOR' project No. 1119) and PNRA (the Italian Antarctic programme) at Concordia station. We thank Olivier Alemany and Jack Triest for advice on this work, and Jérôme Chappellaz for help with the writing.

\section{REFERENCES}

Alemany O and 21 others (2014) The SUBGLACIOR drilling probe: concept and design. Ann. Glaciol., 55(68) (doi: 10.3189/ 2014AoG68A026) (see paper in this issue)

Augustin L and Antonelli A (2002) The EPICA deep drilling program. Mem. Natl Inst. Polar Res., Special Issue 56, 226-244

Fujii $Y$ and 25 others (2002) Deep ice core drilling to $2503 \mathrm{~m}$ depth at Dome Fuji, Antarctica. Mem. Natl Inst. Polar Res., Special Issue 56, 103-116

Johnsen SJ, Dansgaard W, Gundestrup N, Hansen SB, Nielsen JO and Reeh N (1980) A fast light-weight core drill. J. Glaciol., 25(91), 169-174

Johnsen SJ, Gundestrup NS, Hansen SB, Schwander J and Rufli H (1994) The new improved version of the ISTUK ice core drill. Mem. Natl Inst. Polar Res., Special Issue 49, 9-23

Johnson JA, Shturmakov AJ, Kuhl TW, Mortensen NB and Gibson CJ (2014) Next generation of an intermediate-depth drill. Ann. Glaciol., 55(68) (doi: 10.3189/2014AoG68A011) (see paper in this issue)

Kudryashov BB and 9 others (2002) Deep ice coring at Vostok Station (East Antarctica) by an electromechanical drill. Mem. Natl Inst. Polar Res., Special Issue 56, 91-102

Mulvaney R, Alemany O and Possenti P (2007) The Berkner Island (Antarctica) ice-core drilling project. Ann. Glaciol., 47, 115-124 (doi: 10.3189/172756407786857758)

Rand J (1980) 1979 Greenland Ice Sheet Program Phase 1: casing operation. CRREL Spec. Rep. 80-24.

Zhang $N$ and 9 others (2014) Chinese First Deep Ice-Core Drilling Project DK-1 at Dome A, Antarctica (2011-13): progress and performance. Ann. Glaciol., 55(68) (doi: 10.3189/ 2014AoG68A006) (see paper in this issue) 